\title{
Modelling C9orf72-Related Amyotrophic Lateral Sclerosis in Zebrafish
}

\author{
Gabrielle Fortier ${ }^{1}$, Zoé Butti ${ }^{1}$ and Shunmoogum A. Patten ${ }^{1,2, *}$ \\ 1 INRS-Centre Armand-Frappier Santé et Biotechnologie, Laval, QC H7V 1B7, Canada; \\ fortier.gabrielle@gmail.com (G.F.); zoe.butti@iaf.inrs.ca (Z.B.) \\ 2 Centre d'Excellence en Recherche sur les Maladies Orphelines-Fondation Courtois (CERMO-FC), \\ Université du Québec à Montréal (UQAM), Montréal, QC H2X 3Y7, Canada \\ * Correspondence: kessen.patten@iaf.inrs.ca; Tel.: +1-450-687-5010
}

Received: 18 September 2020; Accepted: 17 October 2020; Published: 21 October 2020

\begin{abstract}
A hexanucleotide repeat expansion within the C9orf72 gene is the most common genetic cause of amyotrophic lateral sclerosis (ALS) and its discovery has revolutionized our understanding of this devastating disease. Model systems are a valuable tool for studying ALS pathobiology and potential therapies. The zebrafish (Danio rerio) has particularly become a useful model organism to study neurological diseases, including ALS, due to high genetic and physiological homology to mammals, and sensitivity to various genetic and pharmacological manipulations. In this review we summarize the zebrafish models that have been used to study the pathology of C9orf72-related ALS. We discuss their value in providing mechanistic insights and their potential use for drug discovery.
\end{abstract}

Keywords: ALS; zebrafish; C9orf72; motoneuron

\section{Introduction}

Amyotrophic lateral sclerosis (ALS) is a devastating neurodegenerative disease characterized by the degeneration of the upper motor neurons in the motor cortex and the lower motor neurons in the spinal cord. The disease typically begins with a loss of muscle strength and gradually leads to paralysis. Eventually, most patients will die within two to five years after diagnosis due to weakness of the respiratory muscles [1,2]. The disease occurs with an estimated incidence of 1:100,000 and a lifetime risk of 1:1000. To date, there is no existing treatment that provides significant clinical benefits. Only Riluzole and edaravone are currently approved and can prolong patient survival to a very limited degree [3,4]. Most cases of ALS are sporadic (sALS), but about $10 \%$ are familial (fALS) and have a strong inherited link [5].

In 1993, SOD1 (Cu-Zn superoxide dismutase 1) was the first gene to be associated with fALS [6]. Over the past two decades, several mutations in more than two-dozen genes have been discovered to in ALS, including TARDBP (transactive response to DNA binding protein 43kDa), FUS (fused in sarcoma) [7-9] and C9orf72 (C9orf72-SMCR8 complex subunit) [10,11]. Importantly, an abnormal GGGGCC repeat expansion in the first intron of the C9orf72 gene is the most common genetic cause in ALS patients $[10,11]$. About $40 \%$ of patients with the familial form of ALS and $8-10 \%$ of sALS patients have the C9orf72 hexanucleotide repeat expansion [12]. The hexanucleotide repeat expansion in the C9orf72 gene is also associated with frontotemporal dementia (FTD). Some reports have suggested that ALS patients harbour a higher number of repeats than FTD patients $[13,14]$. Nevertheless, how a repeat expansion in the C9orf72 gene causes neurodegeneration in both ALS and FTD is still poorly understood. Since the discovery of C9orf72 mutation, several animal models including the worm (Caenorhabditis elegans), the drosophila, the mouse and the zebrafish have been used to investigate the C9orf72 form of ALS [15-18]. 
With about 70\% homology between human and zebrafish genes, this animal model appears to be a powerful organism for studying the C9orf72 form of ALS in a vertebrate [19]. Zebrafish as a model is easily genetically manipulated, thus ideal for creating stable transgenic lines to investigate loss- or gain-of-function phenotypes [20,21]. Moreover, the translucency of this model allows simple visualization of the organs/systems of the embryo and to some extent at adult stage in zebrafish casper mutant. In the last few years, the zebrafish has also proven itself for high-throughput drug screening and confirm the capacity of a molecule to rescue neuronal and motility phenotypes, including in ALS models [22]. The use of this vertebrate model may thus offer an exciting opportunity to identify new therapies for the C9orf 72 form of ALS.

This review summarizes what is currently known about the pathogenesis of ALS associated with the C9orf72 gene. An overview of the use of zebrafish as a model system is provided and the different zebrafish models that have been developed over past couple years to study the pathological mechanisms of ALS related to the C9orf72 gene are then discussed.

\section{The C9orf72 Gene Associated with ALS}

The human C9orf72 gene consists of 11 exons and, by alternative splicing, encodes 3 variant transcripts, of which the first and third are translated into the same isoform (481 amino acids) and the second variant is translated into a shorter protein (222 amino acids) [10]. Its sequence is highly conserved between different species including common model systems such as mouse $(98.1 \%)$ and zebrafish (76.0\%). An abnormal GGGGCC repeat expansion in the first intron of the C9orf72 gene is the most common genetic cause in ALS patients [10,11]. The GGGGCC hexanucleotide repeat expansions reside between exon $1 \mathrm{a}$ and $1 \mathrm{~b}$ of the gene. The majority of healthy individuals have $\leq 11$ hexanucleotide repeats in the C9orf72 gene while hundred to several thousand repeats have been reported in ALS/FTD heterozygous carriers $[23,24]$. The pathological expansion repeat-length threshold has not been clearly established but an arbitrary cut-off of carrying 30 repeat-alleles is used in most studies. In the last few years, many developments have occurred to explain how the GGGGCC repeat expansion in the C9orf72 gene is associated with ALS. There are currently 3 proposed pathogenic mechanisms by which the repeat expansions, both sense and antisense $(\text { GGGGCC) })_{n}$, cause ALS. These involves two toxic gain-of-function mechanisms, such as RNA foci accumulation [25] and protein toxicity by aberrant dipeptide repeat protein accumulation [26,27]. Alternatively, repeat expansions cause a decrease in C9orf72 mRNA and protein expression, suggesting loss-of-function by C9orf72 haploinsufficiency may also contribute to C9orf72 ALS.

Reports have shown that abnormal repeat expansion within the C9orf72 causes haploinsufficiency due to its interference with gene transcription $[10,18]$. In addition, cytosine hypermethylation of CG dinucleotides in CpG islands (regions of DNA with significantly higher frequency of CG sequence that regulate transcription at their associated promoters) is an important epigenetic modification that could lead to gene silencing [28]. Indeed, several studies have observed decreased levels of C9orf 72 mRNA and protein in C9orf 72 patients CNS tissues, lymphoblastoid cell lines and neurons derived from patient-derived induced pluripotent stem cells (IPSCs) $[10,29,30]$. To date, the function of the C9orf72 protein still remains unclear, but it has been reported to contain a DENN domain (differentially expressed in normal and neoplasia). The proteins of this family are highly conserved and are GDP/GTP exchange factors (GEF) that activate Rab-GTPases, suggesting that C9orf72 is involved in GTPase activity and the regulation of vesicular transport [31]. Indeed, recent studies have reported that the C9orf72 protein function in a complex with the WDR41 and SMCR proteins as a GEF for Rab8 and Rab39 [32,33]. C9orf72 has also been proposed to play a role in autophagic flux [32,34,35], endosomal trafficking [36-38] and regulating AMPA receptor levels [39]. For example, the SQSTM1 protein (p62) is an autophagy protein and knockdown of C9orf72 in human cell lines showed an accumulation of cytoplasmic aggregates of p62, reflecting an impairment in the autophagosome-lysosome system in these cells $[36,40]$. This observation is consistent with p62-positive inclusion bodies found in ALS and FTD cases [41]. Additionally, knockdown of C9orf72 in human cell lines have shown to result 
in cytoplasmic aggregates of the RNA binding protein, TDP-43 [36,40]. C9orf72 can interact directly with Importin- $\beta 1$ or Ran-GTPase [42] and may play a role in nucleocytoplasmic transport $[43,44]$. Consequently, defects in this pathway may in part account for the mislocalization of TDP-43 from the nucleus to cytoplasm and TDP-43 pathology in ALS.

One of the gain-of-function mechanism hypotheses is that the transcription of the repeat expansion in sense and antisense direction leads to the accumulation of RNA foci [45]. It has been reported in previous studies that patients with the C9orf 72 form of ALS have an accumulation of RNA foci in the brain and the spinal cord [10,25,45-49]. The RNA foci recruit the RNA-binding proteins, inducing their mislocalization and consequently preventing them from performing their normal function, leading to altered RNA metabolism [50]. For example, Lee et al. in 2013 [51] showed that the hnRNP-H protein binds directly to GGGGCC RNA and colocalizes with RNA foci. A list of proteins that bind RNA foci has been identified from previous in vivo and in vitro studies [52].

The other toxic gain-of-function mechanism is the formation of dipeptide repeat proteins (DPRs) due to associated non-ATG (RAN) translation of transcripts in the sense and antisense directions. There are five different DPRs, Gly-Ala (poly-GA), Gly-Arg (poly-GR), Gly-Pro (poly GP), Pro-Ala (poly-PA) and Pro-Arg (poly-PR), forming insoluble aggregates in the nucleus and cytoplasm of the cells [25-27]. Dipeptides containing arginine appear to be particularly toxic to cells, they tend to bind the nucleolus and disrupt RNA splicing and ribosomal biosynthesis [53]. For example, research has shown that poly-GR colocalize with ribosomal subunits, thus affecting translation [54]. Poly-PR, on the other side, seem to bind the nuclear pores and block the nuclear transport of RNA and proteins [55].

The relative contribution of these 3 mechanisms remains to be established as well as the molecular pathways leading to motor neuron degeneration. It is however becoming clearer that haploinsufficiency might contribute to the disease process in synergy with the gain-of-toxicity mechanism [56]. Animal models can then provide answers on the different mechanisms involved and consequently help to develop a specific treatment for patients with C9orf72 ALS.

\section{Zebrafish as A Model System}

Zebrafish as a vertebrate model has received favourable attention from clinicians owing to its many advantages for the study of disease. The rapid, external development of translucent embryos together with low-cost husbandry has sparked the establishment of several models of human diseases in zebrafish [20], and these models often closely resemble the human condition [57]. Additionally, the zebrafish genome has been sequenced [19] and more than $80 \%$ of zebrafish genes have a high degree of conserved gene structures across vertebrate species as well as $50-80 \%$ amino acid identity with most human homologs, including homologs for over $70 \%$ of disease-causing genes. The zebrafish are also especially powerful for genetic manipulation. The majority of their genes can be manipulated by gainand loss-of-function approaches and consequently makes the zebrafish model system particularly valuable for the study of genetic diseases such as ALS.

The easiest and first approach used to study loss-of-function mutations in zebrafish is the injection of antisense morpholino oligonucleotides (MO) to transiently block translation or splicing [58]. This method only allows the phenotype to be observable over a short period of time and can also leads to off-target toxicity $[59,60]$. This is why this technique is more useful for drug testing at the embryonic or larval stages [60]. As for the study of gain-of-function mutations, mRNA injection also provides a transient mutation and consequently presents the same limitation as the injection of antisense morpholino oligonucleotides, i.e., the impossibility to study late-onset phenotypes [60]. The Tol2 transposon system is also popular for integrating a DNA sequence into the zebrafish genome, but it is often necessary to out-crossing over several generations to obtain the desired stable transgenic line [61-63]. However, the development of stable transgenic models does have some limitations, such as ectopic expression, toxic overexpression and variability due to genetic background [64]. Genomic engineering tools, including site-specific transgenesis such as Cre-loxP and the Gal4/UAS system, are an exciting approach for genetic model of ALS in zebrafish $[65,66]$. New genome-editing techniques, 
including transcription activator-like effector nucleases (TALENs) and clustered regularly interspaced short palindromic repeats (CRISPR), have been developed in the last few years and significantly facilitate the study of loss- or gain-of-function mutations in zebrafish $[67,68]$. It is now possible to rapidly generate a zebrafish line with the wanted mutation that will be inherited in order to study its phenotype.

The zebrafish has emerged as a very attractive model for the study of neurological diseases. The basic structure of central nervous system in zebrafish has all the major domains found in the mammalian brain and they produce the same neurotransmitters such as glutamate, GABA, serotonin, dopamine, histamine and acetylcholine [69,70]. Despite some notable differences in the size of the zebrafish brain, the overall cognitive processing and sensory and retinotectal pathways, share an overall homology with humans [71]. Noteworthily, the hippocampus is essential for spatial memory in mammals and is derived developmentally from the medial pallium of the telencephalon [72]. In zebrafish, unlike mammals, the telencephalon is everted and the lateral pallium appears to be structurally homologous to the mammalian hippocampus [73]. Importantly, many of the genes implicated in human neurodegenerative diseases, such as ALS, have been identified in zebrafish. The zebrafish motor system has also some similarities to humans [74,75]; making it relevant model for motor neuron diseases [76,77]. However, an important difference between zebrafish and human is that there is no direct telencephalic projections to the spinal cord (i.e., corticospinal tract) in fish [69]. The zebrafish spinal cord shows a comparable organization to human spinal cord with groups of motor neurons located in specific regions of the spinal cord and innervating specific muscle fibers. Particularly, zebrafish consist of two classes of motoneurons, primary motor neurons and second motor neurons, based on their formation time and target musculature [78]. Primary motor neurons are localized relatively dorsally with large cell bodies and thick axons and they innervate the dorsal, middle, and ventral trunk musculature. On the other hand, secondary motor neurons are located more ventrally in the motor column with smaller cell bodies and thinner axons than primary motor neurons and they innervate the dorsal and ventral musculatures. The zebrafish secondary motor neurons are comparable to human alpha motor neurons and innervate ventral as well as dorsal muscle fibers. Of note, the zebrafish primary motor neurons do not have an equivalent in human and likewise, the human gamma motor neurons are not present in zebrafish. The gamma motor neurons are found in species that have limbs or limb like structures since it is involved in proprioception [69].

Several ALS-causing genes have been studied in zebrafish using loss- or gain-of-function approaches. For instance, overexpression of mutant but not wild-type human SOD1 in zebrafish leads to short motor axons with premature branching associated with deficient swimming in response to touch [79]. Expression upon mRNA injection of human TARDBP mRNA containing one of three missense mutations (TARDBP $P^{\mathrm{G} 348 \mathrm{C}}$, TARDBP ${ }^{\mathrm{A} 315 \mathrm{~T}}$ or TARDBP ${ }^{\mathrm{A} 382 \mathrm{~T}}$ ), but not wild type TARDBP at the same level of expression, resulted in motor behavioural defects and hyperbranched ventral root projections to trunk musculature [80]. Injection of human mutant FUS mRNA resulted in disrupted nuclear import [81] and accumulation in cytosolic stress granules [82] and either mRNA or MO injection resulted in locomotor deficits and ventral root projection abnormalities [83]. Since the discovery of C9orf72 mutation as the most common genetic cause of ALS, it has received much attention and has also evidently been modelled in zebrafish.

Zebrafish has only 1 C9orf72 orthologue (zgc:100846; c13h9orf72) and similarly to human C9orf72 protein-coding transcripts, the zebrafish also possesses 3 protein-coding transcripts giving rise to 2 protein isoforms if different size [18]. Here, we review different C9orf72 zebrafish models (Table 1) that have provided new insights into the pathogenesis of ALS since the abnormal repeat expansion within the C9orf72 gene was identified in 2011 [10,11]. 
Table 1. Summary of the different zebrafish C9orf72 models and their distinct phenotypes.

\begin{tabular}{|c|c|c|c|c|}
\hline Study & Mechanism & Stable or Transient & Method(s) & Cellular and Behavioral Phenotype \\
\hline Ciura et al., (2013) [18] & Loss of function & Transient & Morpholino knockdown C9orf72 & $\begin{array}{l}\text { - Axonopathy (disturbed arborization and shortened axons of motor neuron axons, } \\
\text { - Moto deficits (abnormalities of spontaneous and evoked swimming) }\end{array}$ \\
\hline Lee et al., (2013) [51] & Gain of function & Transient & Overexpression $\left(38 \times\right.$ and $\left.72 \times \mathrm{G}_{4} \mathrm{C}_{2}\right)$ & $\begin{array}{l}\text { - Increase of apoptotic cells throughout } 24 \mathrm{~h} \text { embryo } \\
\text { - RNA foci formation with } 72 \times \mathrm{G}_{4} \mathrm{C}_{2}\end{array}$ \\
\hline \multirow[b]{2}{*}{ Ohki et al., (2017) [84] } & Gain of function & Stable & $\begin{array}{l}\text { UAS responder line expressing } 80 \text { GGGGCC without an ATG } \\
\text { codon (ggggcc80-GFP) was crossed to the Gal4 driver line } \\
\text { SAGFF73A for ubiquitous expression }\end{array}$ & $\begin{array}{l}\text { - } \quad \text { RNA foci formation } \\
\text { A mild cardiac phenotype }\end{array}$ \\
\hline & Gain of function & Stable & $\begin{array}{l}\text { UAS responder line expressing } 80 \text { GGGGCC with an ATG } \\
\text { codon (GA80-GFP) was crossed to the Gal4 driver line } \\
\text { SAGFF73A for ubiquitous expression }\end{array}$ & $\begin{array}{l}\text { - RNA foci formation } \\
\text { - A severe cardiac phenotype } \\
\text { - A reduced circulation of red blood cells } \\
\text { Aggregates of GA80-GFP found in musculature }\end{array}$ \\
\hline Swinnen et al., (2018) [85] & Gain of function & Transient & mRNA Overexpression $\left(35 \times, 70 \times\right.$ and $90 \times \mathrm{G}_{4} \mathrm{C}_{2}$ and $\left.\mathrm{C}_{2} \mathrm{G}_{4}\right)$ & $\begin{array}{l}\text { - Axonopathy (disturbed arborization and shortened axons of motor neuron axons, } \\
\text { - RNA foci formation }\end{array}$ \\
\hline Swaminathan et al., (2018) [86] & Gain of function & Stable & $\begin{array}{c}\text { UAS transgenic line overexpressing } 100 \mathrm{GR} \text { repeats was crossed } \\
\text { to Gal4 driver lines under three different promoters: Hsp: Gal4 } \\
\text { for ubiquitous expression after a heat shock, mnx1: Gal4 for } \\
\text { motor neuron expression, and elavl3: Gal4 for } \\
\text { neuronal expression. }\end{array}$ & $\begin{array}{ll}\text { - } & \text { Reduction in motor neuron length } \\
\text { - Increase apoptotic cells in the spinal cord } \\
\text { - } & \text { An effect on motor neuron development } \\
\text { - Reduction in swimmining behaviour } & \text { Respond poorly to touch }\end{array}$ \\
\hline Yeh et al., (2018) [87] & Loss of function & Transient & $\begin{array}{l}\text { Overexpression of } 2 \text { deletion variants, one containing only de } \\
\text { upstream DENN domain and one containing only the central } \\
\left.\text { DENN domain (c9orf72 } 2^{\mathrm{u}-\mathrm{DENN}} \text { and c9orf72 } \mathrm{c} \text {-DENN }\right)\end{array}$ & $\begin{array}{l}\text { - Altered neuronal network } \\
\text { - } \quad \text { Reson formation in the hindbrain altered } \\
\text { - Spinal motor activity is altered } \\
\text { - Increase of apoptotic cells } \\
\text { Reduced of GTPase activity }\end{array}$ \\
\hline Shaw et al., (2018) [21] & Gain of function & Stable & $\begin{array}{l}\text { Zebrafish model expresses } 89 \text { C9orf72 hexanucleotide } \\
\text { repeat expansions }\end{array}$ & $\begin{array}{ll}\text { - } & \text { RNA foci formation in muscles } \\
\text { - } & \text { Antisense and sense DPRs in muscles and CNS } \\
\text { : } & \text { Reduced swimming behaviour } \\
\text { : } & \text { Mortality } \\
\text { - } & \text { Muscle atrophy } \\
\text { - } & \text { Heat sheuron loss } \\
\text { Heat response is activated }\end{array}$ \\
\hline
\end{tabular}




\section{C9orf72 Zebrafish Models}

\subsection{Loss-of-Function Zebrafish Models}

A zebrafish MO-based model of $c 9$ orf 72 was the first in vivo model to support the loss-of-function hypothesis [18]. The knockdown model was generated using a MO to block the translation of the protein. MO knockdown of $c 9$ orf72 in zebrafish resulted in motor neuron axonopathy, a disturbed arborization and shortened axons at early developmental stages. It also led to motor deficits, in particular, abnormalities in spontaneous and evoked swimming were observed in the knockdown model. Importantly, these phenotypes could be rescued with the expression of human C9orf 72 mRNA, confirming that they were due to the direct effects of loss-of-function of $c 9$ orf 72 . This zebrafish knockdown model exhibited important motor behavioural defects as observed in the disease, allowing us to think that the loss-of-function has a contribution in ALS pathogenesis, but is not exclusive. Of note, no major morphological defects and no experiments examining cytoplasmic aggregation of TDP-43 were reported in this zebrafish knockdown model.

Subsequently, Yeh et al. [87] developed in 2018 two constructs in which two portions of the functional domain DENN of $c 9$ orf 72 were deleted to study its function and to confirm the specificity of the loss-of-function. One of the constructs consisted of only the upstream part of the domain $\left(\mathrm{c} 9 \mathrm{orf}^{\mathrm{u}} \mathrm{u}^{\mathrm{DENN}}\right)$ and the other contained the central region (c9orf72 $\left.{ }^{\mathrm{c}-\mathrm{DENN}}\right)$. The models showed an altered neuronal network and inhibition of the response to stimuli. This work demonstrated that the DENN domain is essential to the function of $c 9$ orf 72 and that a truncated domain has a dominant negative effect. These models were also able to confirm that a deficiency of $c 9$ orf 72 affects axon formation in the hindbrain and spinal motor activity. In addition, an increase in the number of neuronal cells in apoptosis was noted. The models showed significantly reduced GTPase activity compared to controls, which is necessary for vesicular formation and transport. These results suggest the importance of $c 9$ orf 72 for crucial neuronal functions and synapse formation. They reported that the knockdown of Tp53 was able to rescue the apoptosis phenotype but did not completely restore the motility deficit. They then concluded that $c 9$ orf 72 regulates neuronal apoptosis through Tp53. The study by Yeh et al. [87] also established a deletion construct of Cyclin G1 (an N-terminal deletion) (ccng $1^{\Delta 1-40}$ ), and when injected into $c 9$ orf 72 -deficient embryos, it rescued neuronal apoptosis, axonal deficits and motility. This finding suggests that Cyclin G1 upregulation is involved in the pathogenesis of c9orf72-deficient embryos. Thus, the C9orf72-Cyclin G1-Tp53 cascade has an important role in the mechanism behind the disease. Importantly, the zebrafish model with the GTPase activity domain deleted from the C9orf72 protein is sufficient to produce a neurological phenotype similar to the symptoms of ALS patients.

To better understand the role of C9orf72 loss-of-function in ALS pathogenesis, our group recently generated a stable zebrafish line with a reduced expression of c9orf72 [88] using a microRNA-based gene-silencing approach developed for zebrafish [89]. Unlike MO-based knockdown approach, transgenic zebrafish lines that stably express microRNAs designed to target knockdown desired genes of interest have no apparent non-specific toxic effects [90]. Reduced c9orf72 function in zebrafish resulted in motor defects, muscle atrophy, motor neuron loss and mortality in early larval and adult stages [88]. TDP-43 form aggregates in neurons, glial cells [91] and axial skeletal muscle [92] and this TDP-43 pathology is a hallmark of ALS. Using a specific antibody that recognizes the highly homologous human TDP-43 ortholog in zebrafish [93], we importantly observed a mislocalization of TDP-43 from the nucleus to the cytoplasm in skeletal muscles of the c9orf 72 loss-of-function model; consistent with TDP-43 pathology in ALS. Analysis of the structure and function of the neuromuscular junctions (NMJs), revealed a significant reduction in the number of presynaptic and postsynaptic structures and an impaired release of quantal synaptic vesicles at the NMJ in the $c 9$ orf 72 loss-of-function model. Furthermore, a strong downregulation of the synaptic protein, SV2a, as well as marked reduction in the number and size of Rab3a-positive synaptic puncta at NMJ were observed upon reduced $c 9$ orf 72 function in zebrafish, resulting in a reduced rate of synaptic vesicle cycling at the NMJ. 
Altogether, findings from this zebrafish model suggest that loss-of-function mechanisms may underlie defects in synaptic function at NMJ in ALS.

\subsection{Gain of Function Zebrafish Models}

\subsubsection{Hexanucleotide Repeats}

Soon after the discovery of C9orf 72 mutation, Lee et al. (2013) [51] used the zebrafish to determine whether expanded GGGGCC transcripts might be toxic and sequester RNA binding proteins in vivo. They particularly injected EGFP constructs containing $8 \times, 38 \times$ or $72 \times$ repeats into zebrafish embryos to test the length-dependance GGGGCC toxicity. The construct was then expressed only in small portions of the embryos and in a mosaic distribution. While the injection of 8x GGGGCC DNA vector did not increase the number of cells in apoptosis at $24 \mathrm{~h}$ post-fertilization, injection of $38 \times$ and $72 \times$ GGGGCC DNA vectors in zebrafish led to a significant increase in the number of apoptotic cells. Noteworthy, zebrafish injected with $72 \times$ GGGGCC repeats displayed a higher rate of apoptosis compared to those injected with $38 \times$ GGGGCC repeats. However, RNA foci were only detected in embryos injected with $72 \times$ repeats. These embryos were also caspase-3-positive, with clear nuclear condensation and fragmentation, and supporting cell death due to injection of long repeat expansions. This study was thus able to demonstrate in vivo using the zebrafish model that the expression of longer repeats produces RNA foci that initiate cell apoptosis.

The gain-of-function zebrafish C9orf72 model developed by Swinnen et al. in 2018 [85] complements previous studies by showing that overexpression of $35 \times, 70 \times$ or $90 \times$ GGGGCC repeats led to motor axon abnormalities but not overexpression of ten or less repeats. These motor axon defects consisted primarily of reduced axonal growth and aberrant branching at $30 \mathrm{~h}$ post-fertilization. This study also reported for the first time that the same deficit was noticed with the injection of $70 \times$ hexanucleotide antisense repeat RNAs but injection of 35× GGGGCC repeats was less toxic. Importantly, RNA foci were observed in zebrafish injected with $90 \times$ sense and $70 \times$ antisense repeats. To further test whether gain-of-function mechanism relies on RNA toxicity or toxic DPR, or both, they also generated 50x repeats of DPRs containing an ATG start codon. Interestingly, zebrafish expressing DPRs containing arginine, specifically GR and PR, exhibited motor axon abnormalities. However, their analyses indicated that repeat RNA toxicity was independent of DPR toxicity. Since RNA foci are known to bind and sequester RNA-binding proteins, Swinnen and colleagues further took advantage of their model to investigate whether different RNA binding proteins such the Pur-alpha protein $[48,50]$ were also able to bind the toxic RNA repeats, as well as the involvement of p62, a protein involved in autophagy [94]. Expression of Pur-alpha inhibited the development of motor axonal defects induced by sense repeat RNA in zebrafish. It also decreased RNA foci formation and increased the levels of p62 protein. The study demonstrated that, through its modulating effect on p62, Pur-alpha prevented axonopathy induced by repeat RNAs in zebrafish. Importantly, the use of zebrafish as model system provided insights in the occurrence of RNA toxicity independently of DPR toxicity in the pathogenesis of the C9orf72 form of ALS.

A stable C9orf72 transgenic zebrafish model expressing the hexanucleotide repeat expansion was recently developed and characterized by Shaw and colleagues in 2018 [21]. A DNA construct consisting of 89 hexanucleotide repeats under the ubiquitin promotor was injected into the zebrafish embryos to generate the C9orf72 transgenic. Two viable lines were generated (2.2-2 zebrafish line and 2.2-7 zebrafish line) and both exhibited an accumulation of RNA foci and DPRs in muscle and central nervous system (CNS). DPRs were formed by conventional ATG-dependent translation and RAN translation, and in sense and antisense directions. Further characterization of the two 2.2 lines revealed that 2.2-7 zebrafish had a marked reduction in survival rate at 15 days postfertilization and started to exhibit motor behavioural defects as of 5 days postfertilization. Behavioural (swimming) deficits worsened during adulthood and the fish had reduced body weight, consistent with phenotypes observed in ALS. Additionally, muscle atrophy, loss of motor neurons, cognitive impairment, and early 
mortality in young adults as observed in patients with the C9orf72 form of the disease were also noted in the zebrafish model. They also reported that the heat shock response (HSR) was activated in the model, as found in ALS patients, and this activation correlated with the disease progression [95]. This stable C9orf72 transgenic zebrafish model presented the most pathological hallmarks of the ALS and it appeared to be a powerful organism for drug screening.

\subsubsection{Dipeptide Repeat Proteins (DPRs)}

Zebrafish transgenic UAS responder lines with an ATG codon forcing the translation of the poly-GA protein (GA80-GFP) or without an ATG codon (ggggcc80-GFP) were generated by Ohki et al. in 2017 [84] using the Tol2 transposon system. They were interested in establishing a model expressing poly-GA, since this DPR was found in higher quantities in the brain of patients with C9orf72 repeat expansions $[27,96]$. First of all, both lines presented a pathological hallmark of C9ORF72 ALS, consisting of the presence of RNA foci in neurons within the spinal cord. The expression of ggggcc80-GFP had a mild toxicity in zebrafish while the expression of GA80-GFP was highly toxic. Indeed, these fish displayed severe pericardial edema, reduced circulation of red blood cells, and aggregates of GA80-GFP exclusively in the muscles. On the other hand, zebrafish expressing GA80-GFP did not have significant differences in axon length and did not show any vascular patterning defects. However, the endothelial cells in this model were found to be thinner and less well-structured due to a lack of blood perfusion. Ohki and colleagues also injected a MO to specifically targets poly-GA translation, and not the repeat expansion, which this resulted in the rescue of the severe pericardial edema phenotype. This model was used to confirm that poly-GA is highly toxic in zebrafish and suggests the possibility of targeting DPRs as a therapeutic strategy.

After determining that GR was the most toxic of the DPRs, and that 200 GR repeats were largely sufficient to cause significant developmental and motor deficits, Swaminathan et al. [86] developed in 2018 a stable transgenic zebrafish model expressing GR repeats associated with C9orf72. They overexpressed 100 GR repeats under the control of the upstream activation sequence (UAS) using the Tol2 transposon system. In the construct, a GFP sequence under the cmlc2 promoter was used to allow easy identification of the transgenic embryos. Gal4 driver lines under three different promoters were crossed with this transgenic line for cell-specific expression of GR repeats-Hsp: Gal4 for ubiquitous expression after a heat shock, mnx: Gal4 for motor neuron expression, and elavl3: Gal4 for neuronal expression. Ubiquitous expression of GR in zebrafish resulted in severe morphological and motor deficits. On the other hand, GR expression only in motor neurons, led to significant motors deficits with no gross morphological abnormalities. In addition, a decreased in motor neuron length, and an increased in apoptosis cells in the spinal cord were observed in zebrafish expressing GR specifically in motor neurons. However, GR repeat expression did not seem to affect the development of motor neurons. In this study, the zebrafish DPR model demonstrated that GR repeat expression is sufficient to induce motor dysfunction and shortening of motor neuron length in a similar manner to what is observed in ALS patients.

Cytoplasmic accumulation of TDP-43 is a significant neuropathological hallmark in C9-ALS patients. There is indeed a clear association between TDP-43 accumulation and degeneration as well as clinical phenotype [97]. However, none of these gain-of-function zebrafish studies described above reported the presence of cytoplasmic TDP-43 in modelling C9orf72-ALS. Additionally, in these zebrafish models the levels of the C9orf72 protein were not examined. It would have been relevant to check whether expressing the abnormal expansion repeat or dipeptide repeat proteins (DPRs) in zebrafish has an impact on C9orf72 protein levels since some studies have shown a decrease in brain of ALS patients [98].

\section{Conclusions}

ALS is a fatal motor neuron disease and there is an urgent need to develop and assess more effective therapeutics. The GGGGCC hexanucleotide repeat expansion in the C9orf72 gene is the most 
common mutation in both familial and sporadic cases of ALS. The generation of C9orf72 zebrafish models have provided novel insights into the pathogenesis of C9-ALS. It is, however, important to point out that the signature GGGGCC hexanucleotide repeat expansion motif in the C9orf72 is only present in human and its closest relative, the chimpanzee [99]. Although, the expression of pathogenic GGGGCC repeat expansions in zebrafish result in RNA foci and DPR formation that are toxicity as in ALS, perhaps the best approach to accurately model C9orf72-related ALS in zebrafish, is to attempt knock-in the repeats in intron 1 of the zebrafish c9orf72 with CRISPR genome editing approaches in the future.

In addition to providing a better comprehension of why the hexanucleotide repeat expansion in the C9orfF72 gene is pathogenic, the zebrafish has the advantage of being a powerful organism for the screening of therapeutic compounds compared to other animal models. The zebrafish C9orf72 model in the study by Shaw et al. in 2018 [21] is a successful example of its use for the discovery of new drugs in a short period of time. They were able to confirm that Ivermectin, a compound that was effective in their SOD1 zebrafish screen, also decreases HSR activation in the C9 zebrafish model, as well as Riluzole [21,100]. Zebrafish are consequently a powerful tool for drug-discovery by allowing rapid drug screening. The prospect of zebrafish for drug discovery opens new avenues using zebrafish ALS models for finding treatments.

Author Contributions: Conceptualization, S.A.P.; writing-original draft preparation, G.F.; writing-review and editing, S.A.P. and Z.B.; visualization, G.F., Z.B. and S.A.P.; supervision, S.A.P.; project administration, S.A.P.; funding acquisition, S.A.P. All authors have read and agreed to the published version of the manuscript.

Funding: S.A.P. is grateful for the financial support from the Anna Sforza Djoukhadjian research chair in ALS and the Fondation Armand-Frappier. S.A.P. is also supported by an ALS Canada-Brain Canada Career Transition Award, Canadian Foundation for Innovation (CFI), Canadian Institutes of Health Research (CIHR), the Natural Science and Engineering Research Council (NSERC) and a FRQS Junior 1 research scholar. G.F. was supported by a NSERC studentship and a supplementary stipend from SP's research chair fund. Z.B. was supported by a CERMO-FC scholarship.

Conflicts of Interest: The authors declare no conflict of interest.

\section{References}

1. Kiernan, M.C.; Vucic, S.; Cheah, B.C.; Turner, M.R.; Eisen, A.; Hardiman, O.; Burrell, J.R.; Zoing, M.C. Amyotrophic lateral sclerosis. Lancet 2011, 377, 942-955. [CrossRef]

2. Brown, R.H.; Al-Chalabi, A. Amyotrophic Lateral Sclerosis. N. Engl. J. Med. 2017, 377, 162-172. [CrossRef] [PubMed]

3. Bensimon, G.; Lacomblez, L.; Meininger, V.; Bouche, P.; Delwaide, C.; Couratier, P.; Blin, O.; Viader, F.; Peyrostpaul, H.; David, J.; et al. A Controlled Trial of Riluzole in Amyotrophic-Lateral-Sclerosis. N. Engl. J. Med. 1994, 330, 585-591. [CrossRef] [PubMed]

4. Abe, K.; Itoyama, Y.; Sobue, G.; Tsuji, S.; Aoki, M.; Doyu, M.; Hamada, C.; Kondo, K.; Yoneoka, T.; Akimoto, M.; et al. Confirmatory double-blind, parallel-group, placebo-controlled study of efficacy and safety of edaravone (MCI-186) in amyotrophic lateral sclerosis patients. Amyotroph. Lateral Scler. Front. Degener. 2014, 15, 610-617. [CrossRef] [PubMed]

5. Pasinelli, P.; Brown, R.H. Molecular biology of amyotrophic lateral sclerosis: Insights from genetics. Nat. Rev. Neurosci. 2006, 7, 710-723. [CrossRef] [PubMed]

6. Rosen, D.R.; Siddique, T.; Patterson, D.; Figlewicz, D.A.; Sapp, P.; Hentati, A.; Donaldson, D.; Goto, J.; Oregan, J.P.; Deng, H.X.; et al. Mutations in cu/zn superoxide-dismutase gene are associated with familial amyotrophic-lateral-sclerosis. Nature 1993, 362, 59-62. [CrossRef] [PubMed]

7. Sreedharan, J.; Blair, I.P.; Tripathi, V.B.; Hu, X.; Vance, C.; Rogelj, B.; Ackerley, S.; Durnall, J.C.; Williams, K.L.; Buratti, E.; et al. TDP-43 mutations in familial and sporadic amyotrophic lateral sclerosis. Science 2008, 319, 1668-1672. [CrossRef] [PubMed]

8. Kwiatkowski, T.J.; Bosco, D.A.; LeClerc, A.L.; Tamrazian, E.; Vanderburg, C.R.; Russ, C.; Davis, A.; Gilchrist, J.; Kasarskis, E.J.; Munsat, T.; et al. Mutations in the FUS/TLS Gene on Chromosome 16 Cause Familial Amyotrophic Lateral Sclerosis. Science 2009, 323, 1205-1208. [CrossRef] [PubMed] 
9. Vance, C.; Rogelj, B.; Hortobagyi, T.; De Vos, K.J.; Nishimura, A.L.; Sreedharan, J.; Hu, X.; Smith, B.; Ruddy, D.; Wright, P.; et al. Mutations in FUS, an RNA Processing Protein, Cause Familial Amyotrophic Lateral Sclerosis Type 6. Science 2009, 323, 1208-1211. [CrossRef]

10. DeJesus-Hernandez, M.; Mackenzie, I.R.; Boeve, B.F.; Boxer, A.L.; Baker, M.; Rutherford, N.J.; Nicholson, A.M.; Finch, N.A.; Flynn, H.; Adamson, J.; et al. Expanded GGGGCC hexanucleotide repeat in noncoding region of C9ORF72 causes chromosome 9p-linked FTD and ALS. Neuron 2011, 72, 245-256. [CrossRef]

11. Renton, A.E.; Majounie, E.; Waite, A.; Simon-Sanchez, J.; Rollinson, S.; Gibbs, J.R.; Schymick, J.C.; Laaksovirta, H.; van Swieten, J.C.; Myllykangas, L.; et al. A Hexanucleotide Repeat Expansion in C9ORF72 Is the Cause of Chromosome 9p21-Linked ALS-FTD. Neuron 2011, 72, 257-268. [CrossRef] [PubMed]

12. Majounie, E.; Renton, A.E.; Mok, K.; Dopper, E.G.P.; Waite, A.; Rollinson, S.; Chio, A.; Restagno, G.; Nicolaou, N.; Simon-Sanchez, J.; et al. Frequency of the C9orf72 hexanucleotide repeat expansion in patients with amyotrophic lateral sclerosis and frontotemporal dementia: A cross-sectional study. Lancet Neurol. 2012, 11, 323-330. [CrossRef]

13. Dols-Icardo, O.; García-Redondo, A.; Rojas-García, R.; Sánchez-Valle, R.; Noguera, A.; Gómez-Tortosa, E.; Pastor, P.; Hernández, I.; Esteban-Pérez, J.; Suárez-Calvet, M.; et al. Characterization of the repeat expansion size in C9orf72 in amyotrophic lateral sclerosis and frontotemporal dementia. Hum. Mol. Genet. 2014, 23, 749-754. [CrossRef]

14. Suh, E.; Lee, E.B.; Neal, D.; Wood, E.M.; Toledo, J.B.; Rennert, L.; Irwin, D.J.; McMillan, C.T.; Krock, B.; Elman, L.B.; et al. Semi-automated quantification of C9orf72 expansion size reveals inverse correlation between hexanucleotide repeat number and disease duration in frontotemporal degeneration. Acta Neuropathol. 2015, 130, 363-372. [CrossRef]

15. Therrien, M.; Rouleau, G.A.; Dion, P.A.; Parker, J.A. Deletion of C9ORF72 Results in Motor Neuron Degeneration and Stress Sensitivity in C-elegans. PLoS ONE 2013, 8, e83450. [CrossRef]

16. Mizielinska, S.; Gronke, S.; Niccoli, T.; Ridler, C.E.; Clayton, E.L.; Devoy, A.; Moens, T.; Norona, F.E.; Woollacott, I.O.C.; Pietrzyk, J.; et al. C9orf72 repeat expansions cause neurodegeneration in Drosophila through arginine-rich proteins. Science 2014, 345, 1192-1194. [CrossRef]

17. Julien, J.P.; Kriz, J. Transgenic mouse models of amyotrophic lateral sclerosis. Biochim. Et Biophys. Acta-Mol. Basis Dis. 2006, 1762, 1013-1024. [CrossRef] [PubMed]

18. Ciura, S.; Lattante, S.; Le Ber, I.; Latouche, M.; Tostivint, H.; Brice, A.; Kabashi, E. Loss of Function of C9orf72 Causes Motor Deficits in a Zebrafish Model of Amyotrophic Lateral Sclerosis. Ann. Neurol. 2013, 74, 180-187. [CrossRef] [PubMed]

19. Howe, K.; Clark, M.D.; Torroja, C.F.; Torrance, J.; Berthelot, C.; Muffato, M.; Collins, J.E.; Humphray, S.; McLaren, K.; Matthews, L.; et al. The zebrafish reference genome sequence and its relationship to the human genome. Nature 2013, 496, 498-503. [CrossRef] [PubMed]

20. Schmid, B.; Haass, C. Genomic editing open new avenues for zebrafish as a model for neurodegeneration. J. Neurochem. 2013, 127, 461-470. [CrossRef]

21. Shaw, M.P.; Higginbottom, A.; McGown, A.; Castelli, L.M.; James, E.; Hautbergue, G.M.; Shaw, P.J.; Ramesh, T.M. Stable transgenic C9orf72 zebrafish model key aspects of the ALS/FTD phenotype and reveal novel pathological features. Acta Neuropathol. Commun. 2018, 6, 125. [CrossRef] [PubMed]

22. Patten, S.A.; Aggad, D.; Martinez, J.; Tremblay, E.; Petrillo, J.; Armstrong, G.A.B.; La Fontaine, A.; Maios, C.; Liao, M.J.; Ciura, S.; et al. Neuroleptics as therapeutic compounds stabilizing neuromuscular transmission in amyotrophic lateral sclerosis. Jci Insight 2017, 2. [CrossRef] [PubMed]

23. Rutherford, N.J.; Heckman, M.G.; Dejesus-Hernandez, M.; Baker, M.C.; Soto-Ortolaza, A.I.; Rayaprolu, S.; Stewart, H.; Finger, E.; Volkening, K.; Seeley, W.W.; et al. Length of normal alleles of C9ORF72 GGGGCC repeat do not influence disease phenotype. Neurobiol Aging 2012, 33, 2950.e5-2950.e7. [CrossRef] [PubMed]

24. van Blitterswijk, M.; DeJesus-Hernandez, M.; Rademakers, R. How do C9ORF72 repeat expansions cause amyotrophic lateral sclerosis and frontotemporal dementia: Can we learn from other noncoding repeat expansion disorders? Curr. Opin. Neurol 2012, 25, 689-700. [CrossRef] [PubMed]

25. Zu, T.; Liu, Y.; Banez-Coronel, M.; Reid, T.; Pletnikova, O.; Lewis, J.; Miller, T.M.; Harms, M.B.; Falchook, A.E.; Subramony, S.H.; et al. RAN proteins and RNA foci from antisense transcripts in C9ORF72 ALS and frontotemporal dementia. Proc. Natl. Acad. Sci. USA 2013, 110, E4968-E4977. [CrossRef] 
26. Ash, P.E.; Bieniek, K.F.; Gendron, T.F.; Caulfield, T.; Lin, W.L.; Dejesus-Hernandez, M.; van Blitterswijk, M.M.; Jansen-West, K.; Paul, J.W., 3rd; Rademakers, R.; et al. Unconventional translation of C9ORF72 GGGGCC expansion generates insoluble polypeptides specific to c9FTD/ALS. Neuron 2013, 77, 639-646. [CrossRef]

27. Mori, K.; Arzberger, T.; Grasser, F.A.; Gijselinck, I.; May, S.; Rentzsch, K.; Weng, S.M.; Schludi, M.H.; van der Zee, J.; Cruts, M.; et al. Bidirectional transcripts of the expanded C9orf72 hexanucleotide repeat are translated into aggregating dipeptide repeat proteins. Acta Neuropathol 2013, 126, 881-893. [CrossRef]

28. Xi, Z.; Zinman, L.; Moreno, D.; Schymick, J.; Liang, Y.; Sato, C.; Zheng, Y.; Ghani, M.; Dib, S.; Keith, J.; et al. Hypermethylation of the CpG island near the G4C2 repeat in ALS with a C9orf72 expansion. Am. J. Hum. Genet. 2013, 92, 981-989. [CrossRef]

29. Belzil, V.V.; Bauer, P.O.; Prudencio, M.; Gendron, T.F.; Stetler, C.T.; Yan, I.K.; Pregent, L.; Daughrity, L.; Baker, M.C.; Rademakers, R.; et al. Reduced C9orf72 gene expression in c9FTD/ALS is caused by histone trimethylation, an epigenetic event detectable in blood. Acta Neuropathol 2013, 126, 895-905. [CrossRef]

30. Frick, P.; Sellier, C.; Mackenzie, I.R.A.; Cheng, C.Y.; Tahraoui-Bories, J.; Martinat, C.; Pasterkamp, R.J.; Prudlo, J.; Edbauer, D.; Oulad-Abdelghani, M.; et al. Novel antibodies reveal presynaptic localization of C9orf72 protein and reduced protein levels in C9orf72 mutation carriers. Acta Neuropathol. Commun. 2018, 6, 72. [CrossRef]

31. Levine, T.P.; Daniels, R.D.; Gatta, A.T.; Wong, L.H.; Hayes, M.J. The product of C9orf72, a gene strongly implicated in neurodegeneration, is structurally related to DENN Rab-GEFs. Bioinformatics 2013, 29, 499-503. [CrossRef] [PubMed]

32. Sullivan, P.M.; Zhou, X.; Robins, A.M.; Paushter, D.H.; Kim, D.; Smolka, M.B.; Hu, F. The ALS/FTLD associated protein C9orf72 associates with SMCR8 and WDR41 to regulate the autophagy-lysosome pathway. Acta Neuropathol. Commun. 2016, 4, 51. [CrossRef] [PubMed]

33. Corbier, C.; Sellier, C. C9ORF72 is a GDP/GTP exchange factor for Rab8 and Rab39 and regulates autophagy. Small Gtpases 2017, 8, 181-186. [CrossRef] [PubMed]

34. Ugolino, J.; Ji, Y.J.; Conchina, K.; Chu, J.; Nirujogi, R.S.; Pandey, A.; Brady, N.R.; Hamacher-Brady, A.; Wang, J. Loss of C9orf72 Enhances Autophagic Activity via Deregulated mTOR and TFEB Signaling. PLoS Gen. 2016, 12, e1006443. [CrossRef] [PubMed]

35. Yang, M.; Liang, C.; Swaminathan, K.; Herrlinger, S.; Lai, F.; Shiekhattar, R.; Chen, J.F. A C9ORF72/SMCR8-containing complex regulates ULK1 and plays a dual role in autophagy. Sci. Adv. 2016, 2, e1601167. [CrossRef]

36. Sellier, C.; Campanari, M.L.; Julie Corbier, C.; Gaucherot, A.; Kolb-Cheynel, I.; Oulad-Abdelghani, M.; Ruffenach, F.; Page, A.; Ciura, S.; Kabashi, E.; et al. Loss of C9ORF72 impairs autophagy and synergizes with polyQ Ataxin-2 to induce motor neuron dysfunction and cell death. Embo J. 2016, 35, 1276-1297. [CrossRef]

37. Zhang, Y.; Burberry, A.; Wang, J.Y.; Sandoe, J.; Ghosh, S.; Udeshi, N.D.; Svinkina, T.; Mordes, D.A.; Mok, J.; Charlton, M.; et al. The C9orf72-interacting protein Smcr8 is a negative regulator of autoimmunity and lysosomal exocytosis. Genes Dev. 2018, 32, 929-943. [CrossRef]

38. Shi, Y.; Lin, S.; Staats, K.A.; Li, Y.; Chang, W.H.; Hung, S.T.; Hendricks, E.; Linares, G.R.; Wang, Y.; Son, E.Y.; et al. Haploinsufficiency leads to neurodegeneration in C9ORF72 ALS/FTD human induced motor neurons. Nat. Med. 2018, 24, 313-325. [CrossRef]

39. Xiao, S.; McKeever, P.M.; Lau, A.; Robertson, J. Synaptic localization of C9orf72 regulates post-synaptic glutamate receptor 1 levels. Acta Neuropathol. Commun. 2019, 7, 161. [CrossRef]

40. Webster, C.P.; Smith, E.F.; Bauer, C.S.; Moller, A.; Hautbergue, G.M.; Ferraiuolo, L.; Myszczynska, M.A.; Higginbottom, A.; Walsh, M.J.; Whitworth, A.J.; et al. The C9orf72 protein interacts with Rab1a and the ULK1 complex to regulate initiation of autophagy. EMBO J. 2016, 35, 1656-1676. [CrossRef]

41. Al-Sarraj, S.; King, A.; Troakes, C.; Smith, B.; Maekawa, S.; Bodi, I.; Rogelj, B.; Al-Chalabi, A.; Hortobagyi, T.; Shaw, C.E. p62 positive, TDP-43 negative, neuronal cytoplasmic and intranuclear inclusions in the cerebellum and hippocampus define the pathology of C9orf72-linked FTLD and MND/ALS. Acta Neuropathol. 2011, 122, 691-702. [CrossRef] [PubMed]

42. Xiao, S.; MacNair, L.; McGoldrick, P.; McKeever, P.M.; McLean, J.R.; Zhang, M.; Keith, J.; Zinman, L.; Rogaeva, E.; Robertson, J. Isoform-specific antibodies reveal distinct subcellular localizations of C9orf72 in amyotrophic lateral sclerosis. Ann. Neurol. 2015, 78, 568-583. [CrossRef] [PubMed]

43. Jovicic, A.; Paul, J.W., 3rd; Gitler, A.D. Nuclear transport dysfunction: A common theme in amyotrophic lateral sclerosis and frontotemporal dementia. J. Neurochem. 2016, 138 (Suppl. 1), 134-144. [CrossRef] 
44. Zhang, K.; Donnelly, C.J.; Haeusler, A.R.; Grima, J.C.; Machamer, J.B.; Steinwald, P.; Daley, E.L.; Miller, S.J.; Cunningham, K.M.; Vidensky, S.; et al. The C9orf72 repeat expansion disrupts nucleocytoplasmic transport. Nature 2015, 525, 56-61. [CrossRef]

45. Gendron, T.F.; Bieniek, K.F.; Zhang, Y.J.; Jansen-West, K.; Ash, P.E.A.; Caulfield, T.; Daughrity, L.; Dunmore, J.H.; Castanedes-Casey, M.; Chew, J.; et al. Antisense transcripts of the expanded C9ORF72 hexanucleotide repeat form nuclear RNA foci and undergo repeat-associated non-ATG translation in c9FTD/ALS. Acta Neuropathol. 2013, 126, 829-844. [CrossRef]

46. Lagier-Tourenne, C.; Baughn, M.; Rigo, F.; Sun, S.; Liu, P.; Li, H.-R.; Jiang, J.; Watt, A.T.; Chun, S.; Katz, M.; et al. Targeted degradation of sense and antisense C9orf72 RNA foci as therapy for ALS and frontotemporal degeneration. Proc. Natl. Acad. Sci. USA 2013, 110, E4530-E4539. [CrossRef]

47. Mizielinska, S.; Lashley, T.; Norona, F.E.; Clayton, E.L.; Ridler, C.E.; Fratta, P.; Isaacs, A.M. C9orf72 frontotemporal lobar degeneration is characterised by frequent neuronal sense and antisense RNA foci. Acta Neuropathol. 2013, 126, 845-857. [CrossRef] [PubMed]

48. Cooper-Knock, J.; Higginbottom, A.; Stopford, M.J.; Highley, J.R.; Ince, P.G.; Wharton, S.B.; Pickering-Brown, S.; Kirby, J.; Hautbergue, G.M.; Shaw, P.J. Antisense RNA foci in the motor neurons of C9ORF72-ALS patients are associated with TDP-43 proteinopathy. Acta Neuropathol. 2015, 130, 63-75. [CrossRef]

49. DeJesus-Hernandez, M.; Finch, N.A.; Wang, X.; Gendron, T.F.; Bieniek, K.F.; Heckman, M.G.; Vasilevich, A.; Murray, M.E.; Rousseau, L.; Weesner, R.; et al. In-depth clinico-pathological examination of RNA foci in a large cohort of C9ORF72 expansion carriers. Acta Neuropathol. 2017, 134, 255-269. [CrossRef] [PubMed]

50. Gitler, A.D.; Tsuiji, H. There has been an awakening: Emerging mechanisms of C9orf72 mutations in FTD/ALS. Brain Res. 2016, 1647, 19-29. [CrossRef]

51. Lee, Y.B.; Chen, H.J.; Peres, J.N.; Gomez-Deza, J.; Attig, J.; Stalekar, M.; Troakes, C.; Nishimura, A.L.; Scotter, E.L.; Vance, C.; et al. Hexanucleotide Repeats in ALS/FTD Form Length-Dependent RNA Foci, Sequester RNA Binding Proteins, and Are Neurotoxic. Cell Rep. 2013, 5, 1178-1186. [CrossRef] [PubMed]

52. Haeusler, A.R.; Donnelly, C.J.; Rothstein, J.D. The expanding biology of the C9orf72 nucleotide repeat expansion in neurodegenerative disease. Nat. Rev. Neurosci. 2016, 17, 383-395. [CrossRef] [PubMed]

53. Wen, X.; Tan, W.; Westergard, T.; Krishnamurthy, K.; Markandaiah, S.S.; Shi, Y.; Lin, S.; Shneider, N.A.; Monaghan, J.; Pandey, U.B.; et al. Antisense Proline-Arginine RAN Dipeptides Linked to C9ORF72-ALS/FTD Form Toxic Nuclear Aggregates that Initiate In Vitro and In Vivo Neuronal Death. Neuron 2014, 84, 1213-1225. [CrossRef]

54. Zhang, Y.-J.; Gendron, T.F.; Ebbert, M.T.W.; O’Raw, A.D.; Yue, M.; Jansen-West, K.; Zhang, X.; Prudencio, M.; Chew, J.; Cook, C.N.; et al. Poly(GR) impairs protein translation and stress granule dynamics in C9orf72-associated frontotemporal dementia and amyotrophic lateral sclerosis. Nat. Med. 2018, 24, 1136-1142. [CrossRef] [PubMed]

55. Freibaum, B.D.; Lu, Y.; Lopez-Gonzalez, R.; Kim, N.C.; Almeida, S.; Lee, K.-H.; Badders, N.; Valentine, M.; Miller, B.L.; Wong, P.C.; et al. GGGGCC repeat expansion in C9orf72 compromises nucleocytoplasmic transport. Nature 2015, 525, 129-133. [CrossRef]

56. Zhu, Q.; Jiang, J.; Gendron, T.F.; McAlonis-Downes, M.; Jiang, L.; Taylor, A.; Diaz Garcia, S.; Ghosh Dastidar, S.; Rodriguez, M.J.; King, P.; et al. Reduced C9ORF72 function exacerbates gain of toxicity from ALS/FTD-causing repeat expansion in C9orf72. Nat. Neurosci. 2020, 23, 615-624. [CrossRef]

57. Lieschke, G.J.; Currie, P.D. Animal models of human disease: Zebrafish swim into view. Nat. Rev. Genet. 2007, 8, 353-367. [CrossRef]

58. Phillips, J.B.; Westerfield, M. Zebrafish models in translational research: Tipping the scales toward advancements in human health. Dis. Models Mech. 2014, 7, 739-743. [CrossRef]

59. Kok, F.O.; Shin, M.; Ni, C.W.; Gupta, A.; Grosse, A.S.; van Impel, A.; Kirchmaier, B.C.; Peterson-Maduro, J.; Kourkoulis, G.; Male, I.; et al. Reverse genetic screening reveals poor correlation between morpholino-induced and mutant phenotypes in zebrafish. Dev. Cell 2015, 32, 97-108. [CrossRef]

60. Bedell, V.M.; Westcot, S.E.; Ekker, S.C. Lessons from morpholino-based screening in zebrafish. Brief Funct Genom. 2011, 10, 181-188. [CrossRef]

61. Kawakami, K.; Shima, A.; Kawakami, N. Identification of a functional transposase of the Tol2 element, an Ac-like element from the Japanese medaka fish, and its transposition in the zebrafish germ lineage. Proc. Natl. Acad. Sci. USA 2000, 97, 11403-11408. [CrossRef] 
62. Suster, M.L.; Kikuta, H.; Urasaki, A.; Asakawa, K.; Kawakami, K. Transgenesis in zebrafish with the tol2 transposon system. Methods Mol. Biol. 2009, 561, 41-63. [CrossRef]

63. Lissouba, A.; Liao, M.; Kabashi, E.; Drapeau, P. Transcriptomic Analysis of Zebrafish TDP-43 Transgenic Lines. Front. Mol. Neurosci. 2018, 11, 463. [CrossRef]

64. Kabashi, E.; Brustein, E.; Champagne, N.; Drapeau, P. Zebrafish models for the functional genomics of neurogenetic disorders. Biochim. Biophys. Acta-Mol. Basis Dis. 2011, 1812, 335-345. [CrossRef]

65. Lin, H.-J.; Lee, S.-H.; Wu, J.-L.; Duann, Y.-F.; Chen, J.-Y. Development of Cre-loxP technology in zebrafish to study the regulation of fish reproduction. Fish Physiol. Biochem. 2013, 39, 1525-1539. [CrossRef]

66. Halpern, M.E.; Rhee, J.; Goll, M.G.; Akitake, C.M.; Parsons, M.; Leach, S.D. Gal4/UAS transgenic tools and their application to zebrafish. Zebrafish 2008, 5, 97-110. [CrossRef] [PubMed]

67. Hwang, W.Y.; Fu, Y.; Reyon, D.; Maeder, M.L.; Tsai, S.Q.; Sander, J.D.; Peterson, R.T.; Yeh, J.R.J.; Joung, J.K. Efficient genome editing in zebrafish using a CRISPR-Cas system. Nat. Biotechnol. 2013, 31, 227-229. [CrossRef] [PubMed]

68. Hisano, Y.; Ota, S.; Kawahara, A. Genome editing using artificial site-specific nucleases in zebrafish. Dev. Growth Differ. 2014, 56, 26-33. [CrossRef]

69. Babin, P.J.; Goizet, C.; Raldua, D. Zebrafish models of human motor neuron diseases: Advantages and limitations. Prog. Neurobiol. 2014, 118, 36-58. [CrossRef] [PubMed]

70. Panula, P.; Sallinen, V.; Sundvik, M.; Kolehmainen, J.; Torkko, V.; Tiittula, A.; Moshnyakov, M.; Podlasz, P. Modulatory Neurotransmitter Systems and Behavior: Towards Zebrafish Models of Neurodegenerative Diseases. Zebrafish 2006, 3, 235-247. [CrossRef]

71. Tropepe, V.; Sive, H.L. Can zebrafish be used as a model to study the neurodevelopmental causes of autism? Genes Brain Behav. 2003, 2, 268-281. [CrossRef] [PubMed]

72. Eichenbaum, H.; Dudchenko, P.; Wood, E.; Shapiro, M.; Tanila, H. The hippocampus, memory, and place cells: Is it spatial memory or a memory space? Neuron 1999, 23, 209-226. [CrossRef]

73. Rodriguez, F.; Lopez, J.C.; Vargas, J.P.; Broglio, C.; Gomez, Y.; Salas, C. Spatial memory and hippocampal pallium through vertebrate evolution: Insights from reptiles and teleost fish. Brain Res. Bull. 2002, 57, 499-503. [CrossRef]

74. Madgwick, A.; Fort, P.; Hanson, P.S.; Thibault, P.; Gaudreau, M.-C.; Lutfalla, G.; Moeroey, T.; Abou Elela, S.; Chaudhry, B.; Elliott, D.J.; et al. Neural Differentiation Modulates the Vertebrate Brain Specific Splicing Program. PLoS ONE 2015, 10, e0125998. [CrossRef] [PubMed]

75. Stil, A.; Drapeau, P. Neuronal labeling patterns in the spinal cord of adult transgenic Zebrafish. Dev. Neurobiol. 2016, 76, 642-660. [CrossRef]

76. McWhorter, M.L.; Monani, U.R.; Burghes, A.H.M.; Beattie, C.E. Knockdown of the survival motor neuron (Smn) protein in zebrafish causes defects in motor axon outgrowth and pathfinding. J. Cell Biol. 2003, 162, 919-931. [CrossRef]

77. Wood, J.D.; Landers, J.A.; Bingley, M.; McDermott, C.J.; Thomas-McArthur, V.; Gleadall, L.J.; Shaw, P.J.; Cunliffe, V.T. The microtubule-severing protein Spastin is essential for axon outgrowth in the zebrafish embryo. Hum. Mol. Genet. 2006, 15, 2763-2771. [CrossRef]

78. Myers, P.Z.; Eisen, J.S.; Westerfield, M. Development and axonal outgrowth of identified motoneurons in the zebrafish. J. Neurosci. 1986, 6, 2278-2289. [CrossRef]

79. Lemmens, R.; Van Hoecke, A.; Hersmus, N.; Geelen, V.; D’Hollander, I.; Thijs, V.; Van Den Bosch, L.; Carmeliet, P.; Robberecht, W. Overexpression of mutant superoxide dismutase 1 causes a motor axonopathy in the zebrafish. Hum. Mol. Genet. 2007, 16, 2359-2365. [CrossRef]

80. Kabashi, E.; Lin, L.; Tradewell, M.L.; Dion, P.A.; Bercier, V.; Bourgouin, P.; Rochefort, D.; Bel Hadj, S.; Durham, H.D.; Vande Velde, C.; et al. Gain and loss of function of ALS-related mutations of TARDBP (TDP-43) cause motor deficits in vivo. Hum. Mol. Genet. 2010, 19, 671-683. [CrossRef]

81. Dormann, D.; Rodde, R.; Edbauer, D.; Bentmann, E.; Fischer, I.; Hruscha, A.; Than, M.E.; Mackenzie, I.R.; Capell, A.; Schmid, B.; et al. ALS-associated fused in sarcoma (FUS) mutations disrupt Transportin-mediated nuclear import. EMBO J. 2010, 29, 2841-2857. [CrossRef]

82. Bosco, D.A.; Lemay, N.; Ko, H.K.; Zhou, H.; Burke, C.; Kwiatkowski, T.J., Jr.; Sapp, P.; McKenna-Yasek, D.; Brown, R.H., Jr.; Hayward, L.J. Mutant FUS proteins that cause amyotrophic lateral sclerosis incorporate into stress granules. Hum. Mol. Genet. 2010, 19, 4160-4175. [CrossRef] [PubMed] 
83. Kabashi, E.; Bercier, V.; Lissouba, A.; Liao, M.; Brustein, E.; Rouleau, G.A.; Drapeau, P. FUS and TARDBP but not SOD1 interact in genetic models of amyotrophic lateral sclerosis. PLoS Genet 2011, 7, e1002214. [CrossRef] [PubMed]

84. Ohki, Y.; Wenninger-Weinzierl, A.; Hruscha, A.; Asakawa, K.; Kawakami, K.; Haass, C.; Edbauer, D.; Schmid, B. Glycine-alanine dipeptide repeat protein contributes to toxicity in a zebrafish model of C9orf72 associated neurodegeneration. Mol. Neurodegener. 2017, 12, 1-11. [CrossRef]

85. Swinnen, B.; Bento-Abreu, A.; Gendron, T.F.; Boeynaems, S.; Bogaert, E.; Nuyts, R.; Timmers, M.; Scheveneels, W.; Hersmus, N.; Wang, J.; et al. A zebrafish model for C9orf72 ALS reveals RNA toxicity as a pathogenic mechanism. Acta Neuropathol. 2018, 135, 427-443. [CrossRef] [PubMed]

86. Swaminathan, A.; Bouffard, M.; Liao, M.; Ryan, S.; Callister, J.B.; Pickering-Brown, S.M.; Armstrong, G.A.B.; Drapeau, P. Expression of C9orf72-related dipeptides impairs motor function in a vertebrate model. Hum. Mol. Genet. 2018, 27, 1754-1762. [CrossRef] [PubMed]

87. Yeh, T.H.; Liu, H.F.; Li, Y.W.; Lu, C.S.; Shih, H.Y.; Chiu, C.C.; Lin, S.J.; Huang, Y.C.; Cheng, Y.C. C9orf72 is essential for neurodevelopment and motility mediated by Cyclin G1. Exp. Neurol. 2018, 304, 114-124. [CrossRef] [PubMed]

88. Butti, Z.; Giacomotto, J.; Patten, S. Reduced C9orf72 function leads to defective synaptic vesicle release and neuromuscular dysfunction in zebrafish. Res. Sq. 2020. [CrossRef]

89. Giacomotto, J.; Rinkwitz, S.; Becker, T.S. Effective heritable gene knockdown in zebrafish using synthetic microRNAs. Nat. Commun. 2015, 6, 7378. [CrossRef]

90. Leong, I.U.; Lan, C.C.; Skinner, J.R.; Shelling, A.N.; Love, D.R. In vivo testing of microRNA-mediated gene knockdown in zebrafish. J. Biomed. Biotechnol. 2012, 2012, 350352. [CrossRef]

91. Neumann, M.; Sampathu, D.M.; Kwong, L.K.; Truax, A.C.; Micsenyi, M.C.; Chou, T.T.; Bruce, J.; Schuck, T.; Grossman, M.; Clark, C.M.; et al. Ubiquitinated TDP-43 in frontotemporal lobar degeneration and amyotrophic lateral sclerosis. Science 2006, 314, 130-133. [CrossRef]

92. Mori, F.; Tada, M.; Kon, T.; Miki, Y.; Tanji, K.; Kurotaki, H.; Tomiyama, M.; Ishihara, T.; Onodera, O.; Kakita, A.; et al. Phosphorylated TDP-43 aggregates in skeletal and cardiac muscle are a marker of myogenic degeneration in amyotrophic lateral sclerosis and various conditions. Acta Neuropathol. Commun. 2019, 7, 165. [CrossRef] [PubMed]

93. Schmid, B.; Hruscha, A.; Hogl, S.; Banzhaf-Strathmann, J.; Strecker, K.; van der Zee, J.; Teucke, M.; Eimer, S.; Hegermann, J.; Kittelmann, M.; et al. Loss of ALS-associated TDP-43 in zebrafish causes muscle degeneration, vascular dysfunction, and reduced motor neuron axon outgrowth. Proc. Natl. Acad. Sci. USA 2013, 110, 4986-4991. [CrossRef] [PubMed]

94. Almeida, S.; Gascon, E.; Tran, H.; Chou, H.J.; Gendron, T.F.; DeGroot, S.; Tapper, A.R.; Sellier, C.; Charlet-Berguerand, N.; Karydas, A.; et al. Modeling key pathological features of frontotemporal dementia with C9ORF72 repeat expansion in iPSC-derived human neurons. Acta Neuropathol. 2013, 126, 385-399. [CrossRef] [PubMed]

95. Miyazaki, D.; Nakamura, A.; Hineno, A.; Kobayashi, C.; Kinoshita, T.; Yoshida, K.; Ikeda, S.-i. Elevation of serum heat-shock protein levels in amyotrophic lateral sclerosis. Neurol. Sci. 2016, 37, 1277-1281. [CrossRef]

96. Schludi, M.H.; May, S.; Graesser, F.A.; Rentzsch, K.; Kremmer, E.; Kuepper, C.; Klopstock, T.; Arzberger, T.; Edbauer, D.; German Consortium, F.; et al. Distribution of dipeptide repeat proteins in cellular models and C9orf72 mutation cases suggests link to transcriptional silencing. Acta Neuropathol. 2015, 130, 537-555. [CrossRef]

97. Mackenzie, I.R.; Arzberger, T.; Kremmer, E.; Troost, D.; Lorenzl, S.; Mori, K.; Weng, S.-M.; Haass, C.; Kretzschmar, H.A.; Edbauer, D.; et al. Dipeptide repeat protein pathology in C9ORF72 mutation cases: Clinico-pathological correlations. Acta Neuropathol. 2013, 126, 859-879. [CrossRef]

98. Waite, A.J.; Baumer, D.; East, S.; Neal, J.; Morris, H.R.; Ansorge, O.; Blake, D.J. Reduced C9orf72 protein levels in frontal cortex of amyotrophic lateral sclerosis and frontotemporal degeneration brain with the C9ORF72 hexanucleotide repeat expansion. Neurobiol. Aging 2014, 35. [CrossRef] 
99. Iyer, S.; Acharya, K.R.; Subramanian, V. A comparative bioinformatic analysis of C9orf72. PeerJ 2018, 6, e4391. [CrossRef]

100. McGown, A.; Shaw, D.P.J.; Ramesh, T. ZNStress: A high-throughput drug screening protocol for identification of compounds modulating neuronal stress in the transgenic mutant sod1G93R zebrafish model of amyotrophic lateral sclerosis. Mol. Neurodegener. 2016, 11,1-11. [CrossRef]

Publisher's Note: MDPI stays neutral with regard to jurisdictional claims in published maps and institutional affiliations.

(C) 2020 by the authors. Licensee MDPI, Basel, Switzerland. This article is an open access article distributed under the terms and conditions of the Creative Commons Attribution (CC BY) license (http://creativecommons.org/licenses/by/4.0/). 